\title{
The Solution of Irregular Driving Behaviors in Urban Traffic Management
}

\author{
Jingdian Yang \\ School of Political Science and Public Administration \\ University of Electronic Science and Technology of China \\ Chengdu, China
}

\author{
Huiping Zhang \\ School of Political Science and Public Administration \\ University of Electronic Science and Technology of China \\ Chengdu, China
}

\begin{abstract}
The grey zone of drivers' operations violating the traffic rules is called the irregular driving behavior. For traffic departments, it is very hard to monitor and manage. Currently in our country, irregular driving behaviors have a significant impact on traffic safety and due to them, $90 \%$ of traffic accidents were caused. These behaviors are the serious impediment to the regular running of road traffic rules. Because of these behaviors, the road traffic efficiency and the level of road traffic safety are seriously reduced. In this paper, the irregular driving behavior is defined first. By analyzing some recent traffic accidents and irregular driving behaviors, the paper found the rules and proposed some important solutions to help drivers improve driving skills and build a complete driving behavior training system.
\end{abstract}

Keywords-traffic safety; irregular drive; gray zone; traffic management

\section{INTRODUCTION}

With the continuous development of the world economy, the automobile has become an important tool for most people in the world. However, in China, more than 100 thousand people were killed in traffic accidents, which brought many tragedies of family breakdown. According to the statistics of China's traffic accidents in $2011,91.85 \%$ of the 97,000 road traffic accidents were related to drivers' driving behaviors, which prove that road traffic accidents are highly correlated with driving behaviors (seen in "Fig. 1"). To reduce the accidents as much as possible, we have studied these different driving behaviors extensively based on the actual traffic situation in our country. By analyzing the three aspects of drivers, the officials in the departments of traffic management and other interested parties, we found that the cost of drivers' illegal behaviors is low, while the cost of traffic managers' supervision is high and the unclear attitudes of the relevant parties to the illegal behaviors are the primary cause of irregular driving behaviors. In this paper, by studying some typical traffic accident cases, the definition of irregular driving behaviors is given, and at last, the strategies of reducing irregular driving behaviors are proposed.

\section{ANALYSIS OF THE CASES}

Serious security accidents caused by irregular driving behaviors can be seen everywhere. The following two pieces of news are the reports of recent traffic accidents caused by irregular driving behaviors.

\begin{tabular}{|c|c|c|}
\hline The hazards & & Causes of Hazard \\
\hline $\begin{array}{l}\text { Increase the risk } \\
\text { of accidents }\end{array}$ & $\begin{array}{l}\text { Punishment standards are } \\
\text { not clear }\end{array}$ & $\longrightarrow$ Taking chance \\
\hline \multirow{2}{*}{$\begin{array}{l}\text { Resulting in traffic } \\
\text { congestion }\end{array}$} & $\begin{array}{l}\text { Various ways and hidden, } \\
\text { Difficult to manage }\end{array}$ & $\longrightarrow$ huge risk \\
\hline & Causing traffic chaos & Causing traffic \\
\hline $\begin{array}{l}\text { Increase the severity } \\
\text { of the accident }\end{array}$ & $\begin{array}{l}\text { Congestion caused by } \\
\text { more driving behavior }\end{array}$ & $\begin{array}{l}\text { Environmental } \\
\text { pollution problems }\end{array}$ \\
\hline
\end{tabular}

Fig. 1. Risk analysis of irregular driving behaviors.

\section{A. The Incident}

Case 1: Recently, a white car drove on a straight road with right-turn lane to the intersection of Xinhua and Songbai Road, and in order to "save" 55 seconds for red light, the driver of the white car intentionally changed to non-motorized road and made a right turn in the situation of a clear road and the other vehicles waiting for the red light in order.

Unfortunately, the swerve made a crash with an old man on an E- electrombile, which resulted in the old man flying out for several meters and serious injury on his hands and chest.

Case 2: 11:20 pm, Mr Zhang was driving a small car passing Sishui County. When he was going on the Quanyuan Avenue of the county from west to east, his car hit Li who was crossing the road from north to south and after the collision with $\mathrm{Li}$, he hit the pole on the roadside, which caused traffic accidents.

According to Zhang's recalling, at about ten o'clock in the evening of that day, he received a phone call from one of his family who got critical sick, so he immediately drove back home with his parents in his car in hurry. The anxious mood led to his upset. When he was going across the intersection of Quanyuan Avenue at high speed, the opposite car was with the high beam on, so he did not find Li who was riding a bike 
crossing the road. When he saw $\mathrm{Li}$ and tried to take measures to give way, it was too late.

This accident caused serious damage to the two vehicles, Zhang got off to check the situation and found Li lying on the ground motionless, so called the police at the first time and then dialed 120, but unfortunately, Li was seriously injured and dead in the hospital after rescue.

\section{B. Accidents Analysis}

The nature of the accidents: the two incidents above, which led to the tragedy, were due to irregular, improper driving operations, therefore, the party of driving should take full responsibility.

Cause of the accidents: In case 1, when the driver was waiting for the red light he was lack of patience and with the mind of taking chance. It is a common sense that motor vehicles should not occupy non-motorized lanes and turning motor vehicles must yield non-motorized vehicles with courteousness. If a motorized vehicle goes on the nonmotorized road, the driver will be ticked with a fine of 100 yuan, and the violation of the signal instructions can be punished by a fine of 200 yuan and six points of personal driving record. Drivers must get rid of their bad habits, not to succeed for a while resulting in causing harm to others, and bringing losses to themselves.

In case 2, Car lights using is an important function of cars. Compared with low beams, the high beams have the feature of concentration and brightness. With this light, you can shine to higher and farther objects. For night driving, especially in the absence of street lamps, it can enhance the visibility greatly. However, if the high beam was used wrongly, it not only does not increase traffic safety, but increase the probability of occurrence of dangerous accidents.

Currently in China, the phenomenon of high beam abuse is very serious. In fact, wrong high beam using may lead to the instant blind of other drivers, the decrease of ability of speed and distance of perception, and the decrease of the ability of judgment of width. While the high beam of the rear vehicle lights, whether inside or outside, large area of halo will appear in the three rear-view mirrors. Therefore, slowing down the speed as little as possible, when necessary, alternately using high and low beam lights and check your light status frequently, and disuse them in fog weather. If other drivers often turn on the high beam, you can shift your high and low beam to remind them to turn off the high beam.

\section{QUESTIONNAIRE DESIGN AND INVESTIGATION}

\section{A. The Design of Questionnaire}

From the analysis of the two cases above, we know the security loophole caused by bad driving behaviors. "Fig. 1" shows how to count the frequency of irregular driving behaviors, and finding out the rules hidden in these behaviors is the key of the research. So that corresponding countermeasures can be developed. By collecting relevant information about irregular driving behaviors, about 20 items of driving behaviors were identified and each item will define an irregular driving behavior, from which a questionnaire can be designed just as "Table I". In addition to 20 items of behaviors, it was necessary to know their age and driving experience. In this way, we can observe the frequency of each irregular driving behavior as well as the relationship between the behaviors and the driving years and drivers' age, then a preliminary solution can be developed.

\section{TABLE I. QUESTIONNAIRE OF DRIVING BEHAVIOR SURVEY}

\begin{tabular}{|l|l|}
\hline \multicolumn{1}{|c|}{ Driving Proficiency Test } & $\begin{array}{c}\text { Answer Yes or No } \\
\text { for Each Item }\end{array}$ \\
1. Taving good driving technique & \\
2. Having right skill to surpass & \\
3. Changing lanes correctly. & \\
4. Having capability to control car & \\
5. Being never panic even in & \\
unfamiliar environment. & \\
II. Consciousness of Safety & \\
6. Reducing speed when driving & \\
around the schools. & \\
7. Always keeping the safety distance from the & \\
front and rear vehicles. & \\
8. Watching for other vehicles on the road. & \\
III. Self Controlling & \\
9. Tolerating other people's wrong driving & \\
behavior. & \\
10. According to road conditions to slow down & \\
the car. & \\
11. Being never racing with others. & \\
IV. Mood & \\
12. Being angry because of some other people's & \\
behaviors often. & \\
13. Emotions affecting my driving & \\
behaviors. & \\
V. Not Abiding the Rules & \\
14. Without turning on the lights even the \\
visibility is low. \\
15. Changing lane at merging lane. \\
16. Failed to observe pedestrians when making \\
turns \\
17. Changing lanes without watching front and \\
rear vehicles \\
VI. Mistakes \\
18. Driving through the intersection without \\
slowing down. \\
19. Talking to someone while driving. \\
20. Answering the call while driving. \\
\hline Gender & \\
\hline Age & \\
\hline Years of driving & \\
\hline
\end{tabular}

\section{B. Questionnaire Survey}

In August 2016, a questionnaire survey was conducted in the city of Chengdu. The investigation was carried out in the form of papers. Questionnaire and random samples were selected to improve the efficiency of the statistic results. A total of 113 questionnaires were distributed in three days and 100 valid questionnaires were obtained. The recovery rate was about $90 \%$. Among the respondents, $53 \%$ were in the ages of 20 to 30 years old, $29 \%$ were 30 to 40 years old, and $18 \%$ were over 40 years old, while male drivers were about $74 \%$, and female drivers were about $26 \%$. Fifty-four percent of respondents said they drove to work every day, and the remaining drivers driving with varying frequencies. 
According to the survey results, we select several common irregular driving behaviors which often lead to serious accidents to compare the frequencies of accidents. Histograms are used to show the results in "Fig. 2". In this figure we can see that the three most frequently happening irregular driving behaviors include changing lanes without observing, not following the rules of using high beam, and answering the phone during driving. Almost every day we can see these behaviors when we are on road, and traffic accidents in previous cases are also caused by the random lane changing and illegal use of high beam lights. As a result, more sophisticated policies are urgently needed to reduce the incidence of such behaviors.

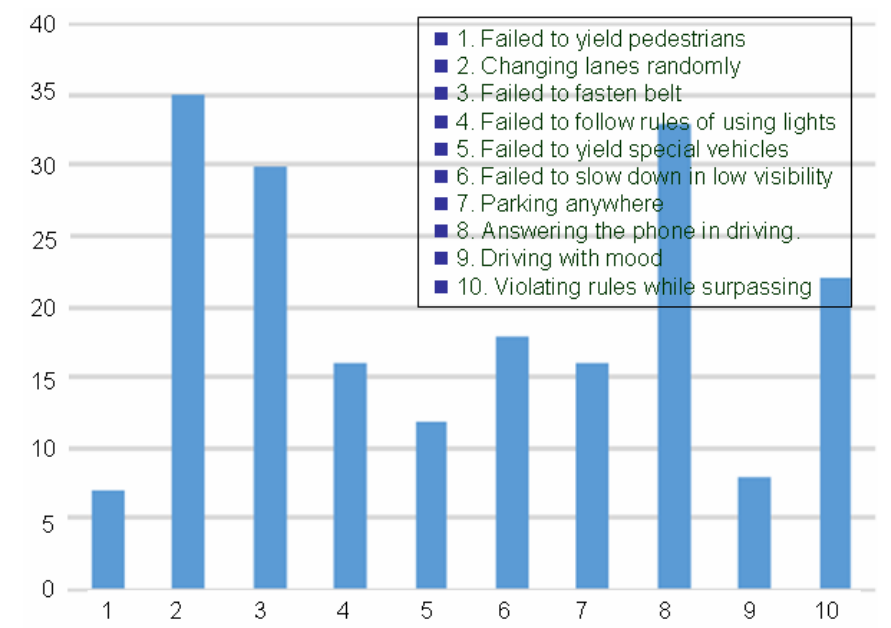

Fig. 2. Comparison of various frequencies of irregular driving behaviors.

\section{POLICY SOLUTIONS AND RECOMMENDATIONS}

\section{A. Refine Traffic Legislation and Regulate the} Responsibilities of Departments of Traffic Administrations

In China, traffic law has been improving since its promulgation. On October 28, 2003, the "People's Republic of China Road Traffic Safety Law" was passed by the fifth session of the Standing Committee of the Tenth National People's Congress, promulgated by the Presidential Decree No. 8 of the People's Republic of China on October 28, 2003, and in May 1, 2004, it was formally implemented. Then it was revised twice separately in 2007 and 2011. Of course, currently the traffic law still has some problems. Such as many items are impractical, the criteria of definition of behaviors are confusing, and supervision is often not in place and so on. All of these problems may lead to the excuse of frequent irregular driving behaviors. Since legislation often lags behind the objective needs, these violations are not effectively constrained. Frequently we can see the behaviors such as change of lanes and illegal use of lights, which break the traffic rules but drivers will not be punished. The officers in departments of traffic administrations have too much discretion, which results in poor supervision to irregular driving behaviors. In addition, the legislative technology is not standardized, so the legal effect is not strong enough, which results in that it has less deterrent on the drivers. The sales of driving points roam on the gray zone result in that many people get rid of punishments after spending money to obtain points. Therefore, the most important thing is to improve China's road traffic legal system so that we can reduce the occurrence of irregular driving behaviors. First of all, starting from the primary and secondary education, all the primary and secondary school teachers should have the training of traffic safety, and then they can educate their students. Traffic safety is related to the whole social security. Currently, since the overall law-abiding quality of citizens in our country needs to be improved, the implementation of these measures is necessary. The key is whether the departments of management are aware of such a meaningful task. Second, we should strengthen the penalties for traffic violations, so that people who think that occasional foul does not matter pay the price. From these experiences, they may not try to violate the rules anymore. If we have similar punishments such as the laws in Singapore that penalties are so heavy, in a short time it should obtain obvious effect.

Departments of Traffic Administration should strengthen the Training for Driving Behaviors

According to the previous questionnaire survey results, in their driving, the six high frequency illegal behaviors: fail to yield to pedestrians or bicycles, without slowing down in the vicinity of the school, free to change the lanes, stop or drive slowly on the driveway at random, driving on urban road with high bean lights on, fail to turn on lights in low visibility and so on, and these behaviors happened with very high probability in the drivers in lower age groups. We can also see that, having no enough driving experience, low skill proficiency are the important reasons to lead to irregular driving behaviors, but the four behaviors including failed to keep safe distance with the vehicle in front, inappropriate to reduce speed in inclement weather conditions, violating rules when surpassing other cars, failed to slow down in front of crosswalk and failed to yielding to special vehicles, are almost committed by drivers with five or more years driving experience drivers, which indicates that even longer time of driving experiences may lead to illegal driving behaviors (as shown in "Fig. 3"). Accordingly, on the one hand, we need to improve the driver training and assessment system such as extending the driving training time, improving driver's qualities and skills, a better testing system for driver's license expired replacement, taking timely measures to correct the driver irregular driving habits. In driving school, I found that the current driving tests have many deficiencies, for example, in the test of second subject, field test requires drivers to maintain the lowest speed throughout the driving, and no other vehicles on the road, but in practical driving, the situation is totally different. For the test of subject 3 , since drivers have very poor time to practice, they don't have the ability to drive on the road even they have got license. Thus, our advice is: 1. Tests of second subject and third subject can be merged into one, so that it is possible to enhance the practicality of the scene test. 2 . Reform of the road test by designating some roads for students to continue practice after they passed the examination so that we can ensure that they can safely drive on the road. In addition, for necessity of safety and civilized driving, we must strengthen the coordination of relevant departments in the management of drivers, such as the strict implementation of rules of the driving school industry 
management, and effectively improving the driving behaviors of civilization. Currently, since numbers of road traffic accidents are caused by the irritable drivers, it's reasonable to have psychological tests for drivers when they are applying driver's licenses so as to prevent the occurrence of irritable drivers to pass the examination easily.

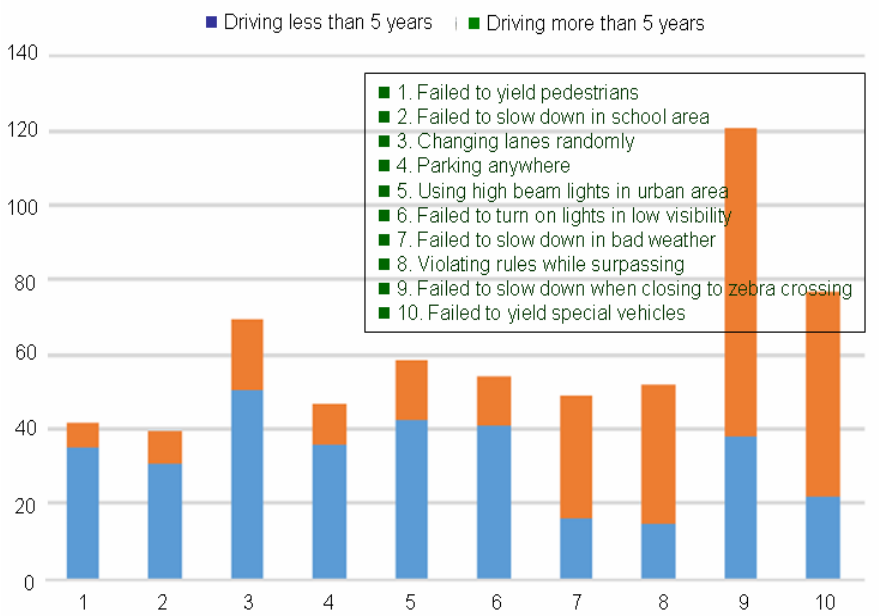

Fig. 3. The comparison of driving age and the frequency of irregular driving behaviors.

\section{B. The Establishment of Socialized Publicity and Education System of Traffic Safety.}

According to the survey results, the frequency of that most of the drivers always violate a certain types of driving regularities is not high, but the frequencies of randomly choosing a certain types of illegal driving behaviors are generally high. In "Fig. 3", we can see that 10 types of irregular driving behaviors confirm this fact.

The driver's emotions are likely to induce illegal driving behaviors; the survey shows that when the illegal driving behavior occurs, the driver's emotions are often anxious or instable. Therefore, we can enforce the psychological quality of the drivers through education, so as to reduce the occurrence of irregular driving behaviors.

In addition, in television and network programs in China, we have a lot of traffic safety publicity and education activities and programs, but most of them are boring. Almost no one is interested in their rigid contents. We propose that the traffic safety programs "Tantan's traffic" in Chengdu TV are relatively new, lively and interesting, and its humorous languages attracted a large number of viewers, which is worth to learn. The establishment of a scientific system of traffic safety education will make all parties related to illegal driving involved in this system. Today, initializing the interactions of traffic of departments of management and drivers, achieving socialized, interactive safety propaganda and education system are imperative.

\section{CONCLUSION}

In order to ensure the safety of every traffic participant, in this paper, the definition of irregular driving behaviors is given according to the actual traffic situation in China. From the cases analysis of the accidents caused by irregular driving behaviors, we have listed the common illegal driving behaviors in our daily life and the preliminary solution for these behaviors is proposed:

- Refine traffic legislation and regulate the responsibility of traffic management;

- Relevant departments should strengthen the driving behavior training. By urging the driving school's reformation, every driver's behaviors will be exactly regularized before they obtain their driver's license;

- Establish a socialized publicity and education system of traffic safety.

\section{REFERENCES}

[1] J. Tang and H. Huang. Study on "Gray Violation" of Driving Behaviors of Urban Traffic. Traffic Information and Security, 2014, 4(10), 201-209.

[2] Baidu Baike: Law of the People's Republic of China on Road Traffic Safety.

[3] L. Sun, Analysis of Tankers' Traffic Accident Cases of Dangerous Items Logistics Engineering and Management, 2014, 3(5), 89-95.

[4] Y. Wang, Feasibility Analysis of Limiting the Use of High Beam. Forum of Guangzhou City Construction College, Oct. 25. 2012.

[5] L. Zhao. Urban Traffic Congestion Management: Policy Comparison and Reference. China Administration, 2013, 5(17), 112-121.

[6] Z. Yin. Studies of the Problems in Traffic Legislation and the Countermeasures. Shandong Jurisprudence, 1992, 7(25): 345-356.

[7] Y. Wu and D. Yu. Traffic Behavior and Safety. Communications Press of China, Jul. 2011 Beijing.

[8] W. Chen, Q. Wu, and Y. Guo, Statistical Analysis on the Influence of Urban Road Dangerous Driving. Statistics and Decision-Making, 2013(14), 107-111.

[9] D. Paker, J. Reason, and S. Manstead, Driving Errors, Driving Violations and Accident Involvement [J]. Ergonomics, 38(5): 1036-1048, 1995.

[10] O. Cheol, P. Park, G. Stephen, and A. Ritchie, Method for Identifying Rear-end Collision, 25(5): 106-118, 1999. 